\title{
PROGRESSIVE RESISTANCE TRAINING IN ELDERLY HIV-POSITIVE PATIENTS: DOES IT WORK?
}

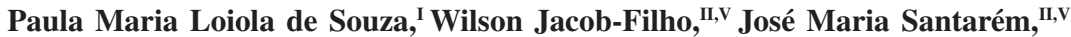

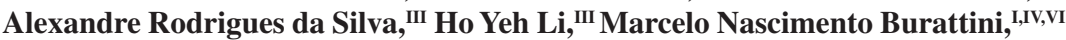

doi: $10.1590 / \mathbf{S 1 8 0 7 - 5 9 3 2 2 0 0 8 0 0 0 5 0 0 0 0 9}$

Souza PML, Jacob-Filho W, Santarém JM, Silva AR, Li HY, Burattini MN. Progressive resistance training in elderly hivpositive patients: does it work? Clinics. 2008;63(5):619-24.

BACKGROUND: Elderly people present alterations in body composition and physical fitness, compromising their quality of life. Chronic diseases, including HIV/AIDS, worsen this situation. Resistance exercises are prescribed to improve fitness and promote healthier and independent aging. Recovery of strength and physical fitness is the goal of exercise in AIDS wasting syndrome.

OBJECTIVE: This study describes a case series of HIV-positive elderly patients who participated in a progressive resistance training program and evaluates their body composition, muscular strength, physical fitness and the evolution of CD4 ${ }^{+}$and $\mathrm{CD} 8^{+}$ cell counts.

METHODS: Subjects were prospectively recruited for nine months. The training program consisted of three sets of 8-12 repetitions of leg press, seated row, lumbar extension and chest press, performed with free weight machines hts, twice/week for one year. Infectious disease physicians followed patients and reported all relevant clinical data. Body composition was assessed by anthropometric measures and dual-energy x-ray absorptiometry before and after the training program.

RESULTS: Fourteen patients, aged 62-71 years old, of both genders, without regular physical activity who had an average of nine years of HIV/AIDS history were enrolled. The strengths of major muscle groups increased $(74 \%-122 \%, p=0.003-0.021)$ with a corresponding improvement in sit-standing and walking $2.4 \mathrm{~m}$ tests $(p=0.003)$. There were no changes in clinical conditions and body composition measures, but triceps and thigh skinfolds were significantly reduced $(p=0.037)$. In addition, there were significant increases in the $\mathrm{CD}^{+}$counts $(\mathrm{N}=151$ cells; $p=0.008)$ and the $\mathrm{CD} 4^{+} / \mathrm{CD}^{+}$ratio $(0.63$ to $0.81, p=0.009)$.

CONCLUSION: Resistance training increased strength, improved physical fitness, reduced upper and lower limb skinfolds, and were associated with an improvement in the $\mathrm{CD} 4^{+}$and $\mathrm{CD} 4^{+} / \mathrm{CD}^{+}$counts in $\mathrm{HIV}$ positive elderly patients without significant side effects.

KEYWORDS: Weight lifting; HIV/AIDS; Elderly; Body composition; Physical fitness.

\section{INTRODUCTION}

According to the Brazilian Institute of Geography

IPathology Department, Faculdade de Medicina, Universidade de São Paulo - São Paulo/SP, Brazil.

II Medical Clinic Department, Faculdade de Medicina, Universidade de São Paulo - São Paulo/SP, Brazil.

IIIInfectious Diseases Department, Faculdade de Medicina, Universidade de São Paulo - São Paulo/SP, Brazil.

IV Discipline of Medical Informatics \& LIM 01/03, Hospital das Clínicas, Faculdade de Medicina, Universidade de São Paulo - São Paulo/SP, Brazil.

${ }^{v}$ Centro de Estudos em Ciências da Atividade Física (CECAFI), Faculdade de Medicina, Universidade de São Paulo - São Paulo/SP, Brazil.

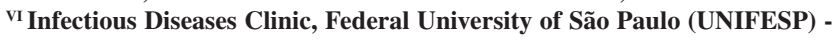
São Paulo/SP, Brazil.

Phone: 55113061.7435

Email: mnburatt@usp.br

Received for publication on June 19, 2008

Accepted for publication on June 26, 2008 and Demography (Instituto Brasileiro de Geografia e Estatística or IBGE), ${ }^{1}$ Brazil presents an aged population that corresponds to $9.7 \%$ of its total population. The aging index grew from 0.11 in the 1980 's to 0.25 in $2004 .^{1}$ These values show that Brazilian society is aging, but it can still be considered young when compared to other countries, such as Italy, Japan and Germany, which present larger elderly populations. ${ }^{1}$

The aging process has been widely studied in the last decade, enhancing the understanding of diseases that affect elderly people and, therefore, promoting a shift towards a healthier and more independent aging process. Amongst the physiological modifications observed during aging, the loss of functional capabilities and the modifications of metabolic functions are the most important. ${ }^{2,3}$ 
Studies show that regular physical activity is a key feature for more healthful aging. ${ }^{3,4}$ The risk of disease and health problems can decrease with exercise, ${ }^{3,4}$ which may also help the immune system recover in the elderly, reducing the prevalence of infections and neoplasias among exercisers. ${ }^{3}$ Regular exercise can also decrease fat mass and increase lean mass and aerobic performance. ${ }^{5}$

In general, physical exercise has proven to be beneficial for diseases associated with aging, and these benefits may result from any type of physical activity. However, resistance exercises, as the most effective method for developing muscle strength, have shown specific benefits and are currently prescribed by many major health organizations to improve health and fitness. ${ }^{3}$

When sedentary for a long time, elderly people can present significant alterations in body composition and physical fitness, compromising their quality of life in many important ways. Some chronic diseases, for instance AIDS, can even worsen this situation because such diseases exacerbate the effects of aging on body composition and muscle strength.

Recovering strength and physical fitness is the major goal of exercise in patients with AIDS wasting syndrome. Therefore, a resistance training program could form the basis of an exercise prescription for this group of patients. It should be progressive, so resistance increases as the patient becomes stronger. ${ }^{6}$

Some studies involving HIV-positive adults and resistance training have been carried out, but no studies focusing on elderly HIV-positive people have been conducted yet. ${ }^{7-9}$ The present study aims to describe a case series of HIV-positive elderly people who participated in a progressive resistance training program and to evaluate their body composition, muscular strength, physical fitness and evolution of $\mathrm{CD} 4^{+}$ and $\mathrm{CD} 8^{+}$cell counts.

\section{METHODS}

This is a case series study ${ }^{10}$ describing the effects of a one-year resistance training program among elderly HIVpositive patients. All HIV-positive patients, 60 or more years old and who were being treated for HIV/AIDS at the Hospital das Clínicas da Faculdade de Medicina da Universidade de São Paulo by the end of 2003 were invited to participate in this study. The first invitation was made either by telephone or directly at the medical consultation, followed by written correspondence to their homes. After obtaining their written agreement to participate in the research, orientation to the program was provided. The recruitment period extended from November 2003 to July 2004. The institutional research ethical committee approved the study after review, and all participants signed a formal written, informed consent form.

Inclusion criteria were the following: HIV-positive, older than 60 years by July 2003, lack of regular physical activity practice and agreement to participate. Both genders were accepted.

Exclusion criteria were the following: medical contraindication to perform exercises, any physical condition that limited resistance of training, use of corticosteroids or other anabolic steroids and non-adhesion to the training program (defined as an absence of at least three consecutive months from the training program).

After the initial interview, patients were questioned about the time since their HIV diagnosis, in addition to their health and life conditions. Additionally, relevant clinical data were obtained from patients' record forms. Patients were clinically followed by their own infectious disease-specialized physicians throughout the study. Both immunological evaluations, by means of T-CD4 ${ }^{+}$and $\mathrm{T}-\mathrm{CD} 8^{+}$lymphocytes counts, and virological evaluations, by means of quantitative HIV-RNA PCR, were standard practice and performed every four months for those who attended the clinic.

The anthropometric measurements collected in this study were body mass, circumferences and skinfolds, assessed according to protocols previously described. ${ }^{11,12}$ Body composition assessments by dual-energy $x$-ray absorptiometry (DEXA) were carried out before and after the training period, following the methods described by Ellis. ${ }^{13}$

The supervised progressive resistance training program consisted of four different exercises (muscles trained): 1) leg press (quadriceps), 2) seated row (latissimus dorsi), 3) lumbar extension (paravertebral muscles), and 4) chest press (pectoralis major). Exercises were performed using free weight machines (Maxiflex Biodelta, Joinville, SC, Brazil). Exercises were performed in three sets of 8-12 repetitions at light, moderate and heavy resistance, respectively, with 1-2 minutes of rest between the series, twice a week for one year, from March 2004 to September 2005. According to our protocol, adapted from the American Geriatric Society recommendations, ${ }^{14}$ all subjects were submitted to five training sections, prior to the beginning of the training program, in order to assure an adequate and safe evaluation of their initial working load. ${ }^{15}$ Sub-maximum weight supported (in the heavy resistance series) was defined as the maximum weight lifted smoothly without Valsalva maneuver, apnea or isometry. For the purposes of this work, it was a surrogate of muscular strength.

Patients were also submitted to two functional tests every four months in order to better evaluate their physical performance evolution along the training period. The tests included an assessment of a timed 2.4-meter walk (walking 
$2.4 \mathrm{~m}$ ) at a normal pace and a timed test of five repetitions of rising from a chair and sitting down (sit-standing), according to the protocol described by Guralnik et al. ${ }^{16}$

Data were recorded and stored in an Excel $^{\circledR}$ sheet and analyzed with Statistica for Windows ${ }^{\circledast}$, version 7.5. The differences seen in strength, anthropometric variables and functional tests before and after the one-year training period were compared with Wilcoxon matched pair test, considering the entire sample and controlling for age and gender effects as well as for baseline HIV infection stage and co-morbidity presented by them. The significance level was set at $5 \%$.

\section{RESULTS}

One hundred and eight HIV-positive patients, more than 60 years old by the end of 2003 , were invited to participate in the study. Of those, two refused, two died, and two did not have the physical condition necessary to participate in the training program. In addition, 88 patients did not show interest or were unable to participate in the study because they lived outside São Paulo City and/or presented poor clinical conditions. Thus, only 14 patients, aged 62-71 years (mean \pm sd: $65.6 \pm 2.9$ ), of both genders and with average of nine years duration of HIV infection, agreed to participate. In addition, three of these patients abandoned the training program for more than three months and were excluded from the study protocol. Therefore, only 11 completed the period of training and remained in the study for the final analysis. Among those 11 participants, only one did not report previous use of Highly Active Antiretroviral Therapy (HAART), and four presented previous histories of HIV-associated diseases. On average, patients attended $76.4 \%$ of the intended exercise sessions. Table 1 summarizes the baseline demographic and clinical characteristics of the sample.

Table 2 shows the weight load variation after one year of resistance training program with four different exercises. The average load of each muscular group trained increased significantly: leg press $97 \%, p=0.004$; seated row $78 \%, p$ $=0.021 ;$ lumbar extension $122 \%, p=0.003$; and chest press $74 \%, p=0.003$.

The increased muscular strength is reflected in the results of the two functional tests performed. There was a significant reduction in both the sit-standing $(2.00 \times 1.57 \mathrm{~s}, p=0.003)$ and the walking $2.4 \mathrm{~m}(9.25 \times 6.58 \mathrm{~s}, p=0.003)$ times when comparing before and after the year of resistance training, as shown in Figures 1 and 2.

Weight did not change significantly, nor did most of the body composition measures analyzed (see Table 3 ), with the exception of triceps and thigh skinfolds, which both showed significant reduction $(11.4 \times 9.2 \mathrm{~mm}, p=0.037$; and $13.9 \times$ $12.1 \mathrm{~mm}, p=0.011$, respectively), as shown in Figure 3 .

The differences seen in all variables described above were not affected by age, gender, HIV infection stage or comorbidity with the exception of strength variation in seated

Table 1 - Baseline demographic and clinical characteristics of the analyzed sample

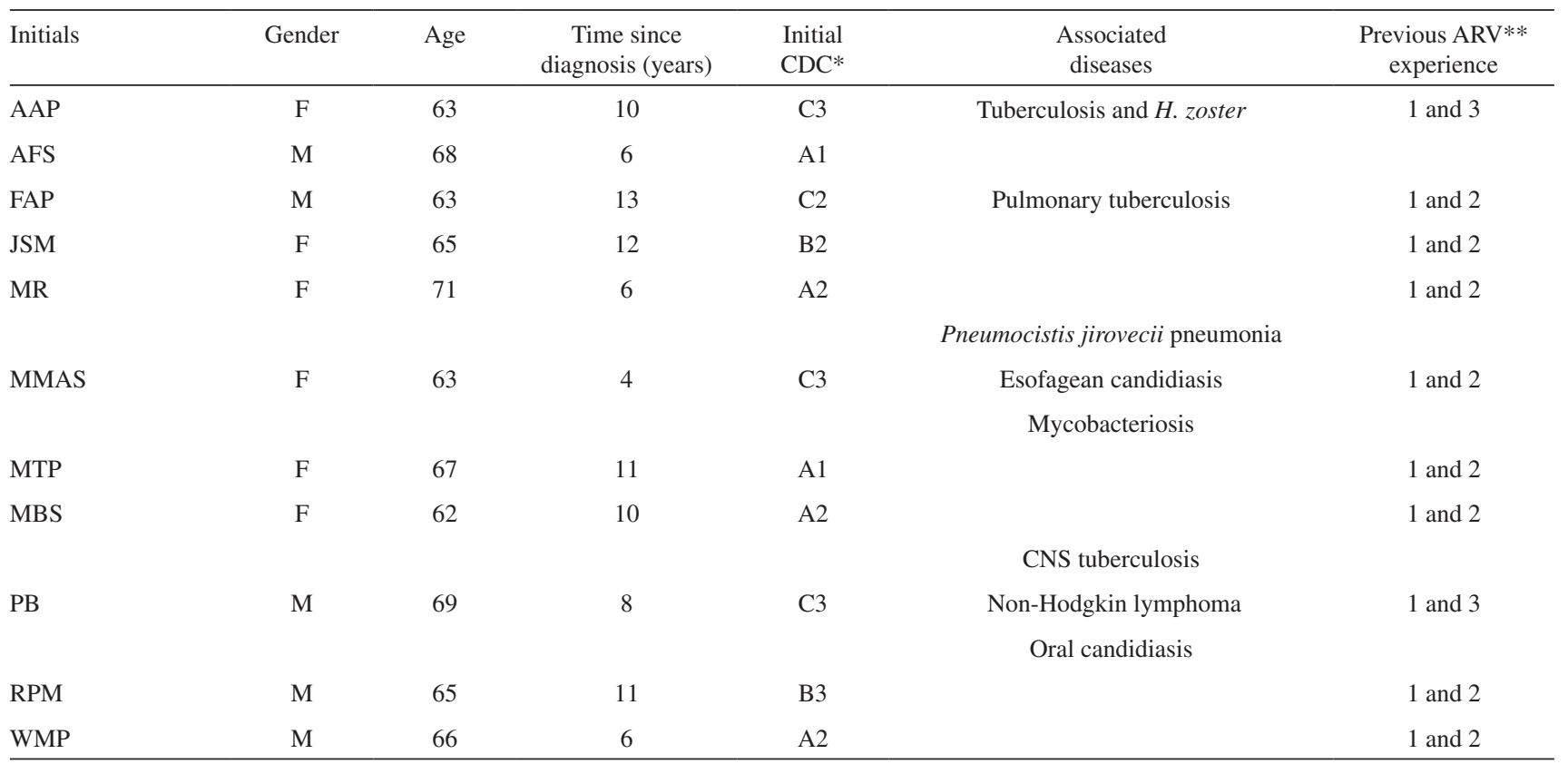

* CDC $=$ Centers for Disease Control Case Definition for HIV infection, Atlanta, USA, $1993 .{ }^{15} ; 1=$ nucleoside reverse transcriptase inhibitors; $2=$ nonnucleoside reverse transcriptase inhibitors; $3=$ protease inhibitors. 
Table 2 - Load variations of four exercises after one year of resistance training

\begin{tabular}{|c|c|c|c|c|c|c|c|c|c|c|c|c|}
\hline \multirow[t]{2}{*}{ Loads (kg) } & \multicolumn{3}{|c|}{ Leg press } & \multicolumn{3}{|c|}{ Seated row } & \multicolumn{3}{|c|}{ Lumbar extension } & \multicolumn{3}{|c|}{ Chest press } \\
\hline & Before & After & $\Delta$ & Before & After & $\Delta$ & Before & After & $\Delta$ & Before & After & $\Delta$ \\
\hline Mean & 33.8 & 63.0 & 29.2 & 25.0 & 45.5 & 20.5 & 31.2 & 66.5 & 35.3 & 12.5 & 20.7 & 8.3 \\
\hline SD & 10.7 & 19.1 & & 6.2 & 21.8 & & 9.1 & 13.8 & & 6.9 & 8.3 & \\
\hline Median & 31.0 & 60.0 & 29.0 & 22.5 & 38.2 & 18.2 & 28.3 & 60.0 & 35.0 & 10.3 & 17.5 & 7.0 \\
\hline Minimum & 20.7 & 32.5 & -2.5 & 19.0 & 0.0 & -20.7 & 17.8 & 48.7 & 24.2 & 7.5 & 12.5 & 4.2 \\
\hline Maximum & 48.7 & 95.0 & 56.3 & 35.0 & 80.0 & 46.9 & 45.8 & 89.2 & 49.4 & 30.8 & 35.0 & 18.2 \\
\hline $25^{\text {th }}$ percentile & 22.5 & 50.0 & 14.2 & 20.0 & 37.5 & 14.5 & 24.3 & 60.0 & 25.0 & 7.5 & 15.0 & 5.0 \\
\hline $75^{\text {th }}$ percentile & 45.0 & 78.1 & 46.7 & 32.5 & 68.1 & 33.1 & 40.8 & 83.1 & 42.2 & 15.0 & 25.3 & 10.3 \\
\hline$p$-value $*$ & & 0.004 & & & 0.021 & & & 0.003 & & & 0.003 & \\
\hline
\end{tabular}

* Willcoxon matched pair test

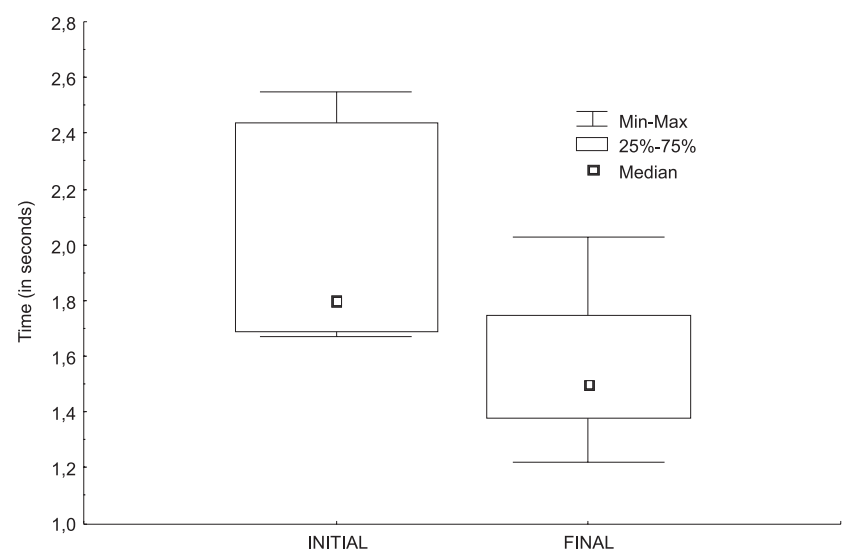

Figure 1 - Time necessary to walk $2.4 \mathrm{~m}$ before and after one year of resistance training $(p=0.003)$

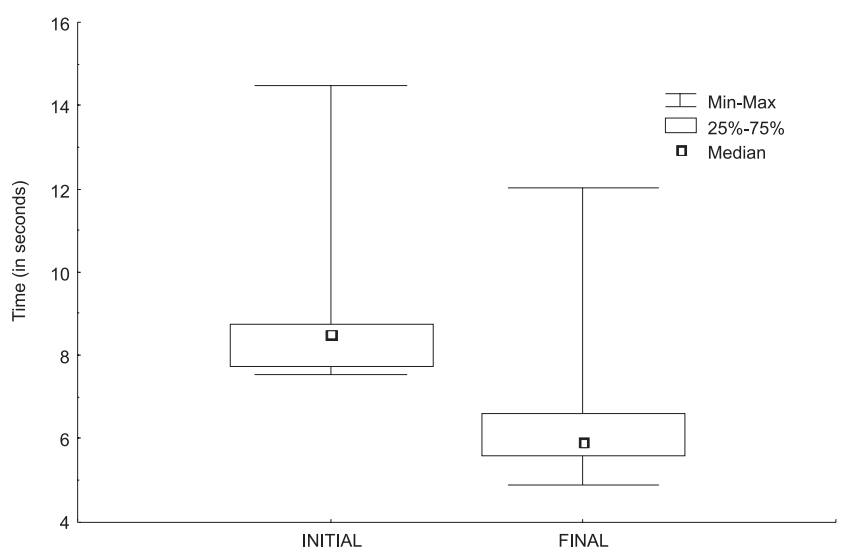

Figure 2 - Time necessary to sit-standing before and after one year of resistance training $(p=0.003)$

Table 3 - Variation of anthropometric measures before and after one year of resistance training

\begin{tabular}{lcccc}
\hline Anthropometric measures & Before & After & Variation $(\Delta)$ & $p$-value* \\
\hline Body weight (kg) & 60.17 & 60.09 & -0.08 & 0.84 \\
Body mass index & 22.80 & 23.00 & 0.20 & 0.65 \\
Bone mineral content (g) & $1,430.30$ & $1,405.6$ & -24.70 & 0.16 \\
Lean mass (g) & $41,384.30$ & $41,942.20$ & 557.90 & 0.66 \\
Fat mass (g) & $9,555.10$ & $9,527.10$ & -28.00 & 0.93 \\
\hline
\end{tabular}

* Willcoxon matched pair test

row, which increased more among men $(p=0.02)$.

In addition, no significant adverse effect related to the exercise program or any new (or worsening of previously existent) AIDS-related condition developed during the training period.

Finally, with respect to the evolution of virological and immunological markers of HIV infection, all but two patients (patients AAP and AFS of Table 1) had persistently undetectable viral loads. Also, there were significant increases in the $\mathrm{CD} 4^{+}$cell counts $(388 \pm 163$ before vs. $\mathrm{x} 539$ \pm 225 after, $\Delta=151$ cells, $p=0.008)$ and in the $\mathrm{CD}^{+} / \mathrm{CD}^{+}$ ratio ( 0.63 to $0.81, p=0.009)$ and a non-significant increase in the $\mathrm{CD} 8^{+}$cell counts $(762 \pm 423$ before vs. $\mathrm{x} 816 \pm 376$ after, $\Delta=54$ cells; $p=0.464)$.

\section{DISCUSSION}

To the best of our knowledge, this is the first study to 


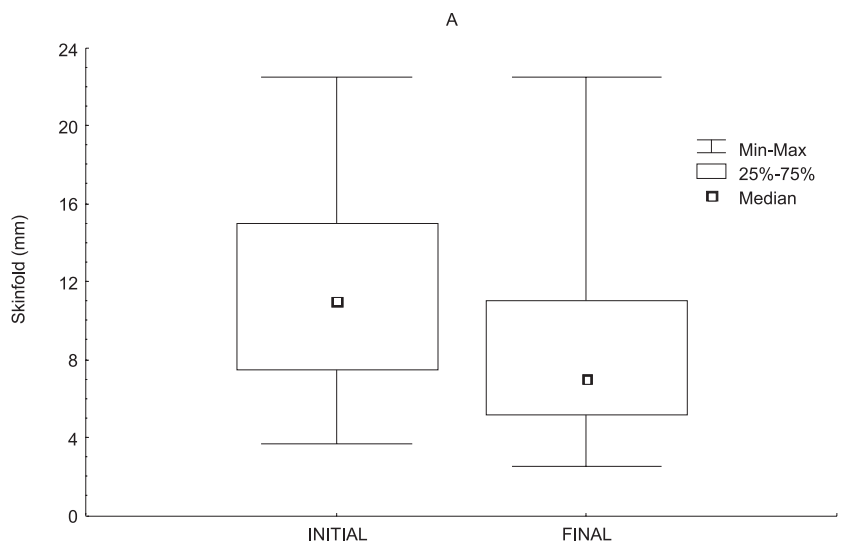

Figure 3 - Triceps (A) and thigh (B) skinfolds before and after one year of resistance training

investigate the influence of progressive resistance training in HIV-infected people older than 60 years. The training protocol followed the recommendations of American College of Sports and Medicine ${ }^{3}$, which suggest a progression model for resistance exercises in healthy, older adults. For this population, the studies show favorable changes regarding the risk factors associated with osteoporosis, heart disease, cancer and diabetes and also show a reduction in fat mass and an increase in lean mass and muscular strength. ${ }^{4,18}$

As mentioned in the results, only 11 out of 14 HIVinfected people, aged 60 years or more, completed the oneyear training period. Among them, those who experienced some intercurrence during the training period did not suffer deconditioning. When they restarted training, it was easy for them to continue with the same loads they used before.

A substantial strength increase was seen for all exercises in every patient who completed the training program regardless of their age, gender, baseline HIV infection stage or the presence of any HIV/AIDS-associated morbidity, and this was not different for the only patient who did not use antiretrovirals. The average increase in the load supported after 12 months of resistance training varied from 74 to $122 \%$ ( $p \leq 0.003-0.021)$, depending on the muscular group considered. In addition, the functional tests results, which showed significant improvement in the sit-standing and walking $2.4 \mathrm{~m}$ times $(p=0.003)$, reflected this increase. Before starting the training program, the patients were all sedentary and, in spite of having different baseline HIV infection stages and co-morbidity histories, they had stable clinical conditions. Thus, the strength increase observed could hardly be attributed to any other cause but the training program. The strength increment is important for the quality of life of the aged population because it improves biomechanics and cardiovascular responses, thus facilitating daily life activities.
Our sample was comprised of elderly HIV-positive individuals who were experiencing a stable clinical evolution, almost all of them under HAART treatment for more than one year prior to the beginning of the study. However, despite the significant benefits associated with HAART, HIV infection and its therapy have been associated with the development of several metabolic complications: increased central adiposity, peripheral lipoatrophy, peripheral insulin resistance, diabetes, dyslipidemia and hypertriglyceridemia, osteoporosis and osteopenia. These complications may predispose patients to a premature risk of metabolic and cardiovascular diseases. ${ }^{19}$ In addition, aging predisposes them to the same biological effects, ${ }^{20}$ and one could expect that aging could act as a potentiator of those HIV infectionand HAART-related alterations. On the other hand, resistance training improves many of those alterations. ${ }^{2}$

In our study, no changes were seen either in body composition, assessed by DEXA after 12 months of resistance training, or in anthropometric measures with the exceptions of triceps $(p=0.037)$ and thigh $(p=0.011)$ skinfolds. Weight did not change significantly $(p=0.84)$ either. We are well aware that this could be simply an effect of the lack of power of the study due to the small size. However, the low intensity of the alterations seen in Table 3 and the fact that some of them are opposite to what is the expected effect of resistance training could suggest that the absence of statistical significance may be true.

Finally, the effects of exercises on immune function have been studied in both adult and elderly healthy populations, showing that moderate levels of training are helpful for both populations..$^{21,22}$ In our study, assessment of immune response, which is usually performed for HIV patients, showed a significant increase in both $\mathrm{CD} 4^{+}$counts $(\Delta=151$ cells, $p=0.008)$ and in the $\mathrm{CD} 4^{+} / \mathrm{CD}^{+}$ratio $(0.63$ to 0.81 , $p=0.009)$ in addition to a non-significant increase in the CD $8^{+}$counts $(\Delta=54$ cells; $p=0.464)$ after one year of resistance training. Those are important variations in the number of cells, considering that there were no significant changes in viral load or HAART use among them during the training period. Almost all patients had undetectable viral load and were on HAART therapy before, during and after the training period. Therefore, the observed changes in the numbers of $\mathrm{CD}^{+}$and $\mathrm{CD} 8^{+}$cells, together with the absence of new HIV-related morbidity, should most probably be attributed to their stable HIV infection conditions.

In conclusion, despite the relatively small sample, our results indicate that a progressive resistance training program can benefit elderly people living with HIV without any major adverse effects or worsening of HIV/AIDS related conditions, which favors its recommendation for such a population. 


\section{ACKNOWLEDGMENTS:}

The authors acknowledge Doctors Olavo Munhoz Leite and Aluisio Augusto Cotrim Segurado for their support during the research activities carried out Casa da AIDS do Hospital das Clínicas da Faculdade de Medicina da Universidade de São Paulo. The authors also acknowledge Leila Strazza and Miss Elizabeth Carvalho Freire for their help in discussing some aspects of the organization and writing of the manuscript.

\section{REFERENCES}

1. Instituto Brasileiro de Geografia e Estatística - IBGE. Síntese de Indicadores Sociais 2005. http://www.ibge.gov.br/home/ estatistica/populacao/condicaodevida/indicadoresminimos/ sinteseindicsociais2005/indic_sociais2005.pdf (Apr 12, 2006).

2. Hunter GR, McCarthy JP, Bamman MM. Effects of resistance training on older adults. Sports Med. 2004;34:329-48.

3. Kraemer WJ, Adams K, Cafarelli E, Dudley GA, Dooly C, Feigenbaum MS, et al. American College of Sports Medicine. Position Stand on Progression models in resistance training for healthy adults. Med. Sci. Sports Exerc. 2002;34:364-80.

4. Winett RA, Carpinelli RN. Potential Health - related benefits of resistance training. Preventive Medicine. 2001;33:503-13.

5. Utter AC, Nieman DC, Shannonhouse EM, Butterworth DE, Nieman $\mathrm{CN}$. Influence of diet and/or exercise on body composition and cardiorespiratory fitness in obese women. Int J Sport Nutrition. $1998 ; 8: 213-22$

6. Roubenoff R. Acquired immunodeficiency syndrome wasting, functional performance and quality of life. Am J Manag Care. 2000;6:1003-16.

7. Roubenoff R, McDermott A, Weiss L, Wood M, Bloch R, Gorbach S Short-term progressive resistance training increases strength and lean body mass in adults infected with human immunodeficiency virus. AIDS. 1999;13:231-9.

8. Lox CL, McAuley E, Tucker RS. Aerobic and resistance exercise training effects on body composition, muscular strength, and cardiovascular fitness in an HIV-1 population. Int J Behav Med. 1996;3:55-69.

9. Jones SP, Doran DA, Leat PB, Maher B, Pirmohamed M. Short-term exercise training improves body composition and hyperlipidaemia in HIV-positive individuals with lipodystrophy. AIDS. 2001;15:2049-51.

10. Grimes DA \& Schulz FK. Descriptive studies: what they can and cannot do. The Lancet. 2002;359:145-9.

11. Callaway W, Chumlea, WC, Bouchard C, Himes JH, Lohman TG, Martin $\mathrm{AD}$ et al. Circumferences. In: Lohman TG, Roche AF, Martorell R (eds). Anthropometric Standardization Reference Manual. Champaing, Illinois: Human Kinectics; 1988. p.39.

12. Harrison GG, Buskirk ER, Carter JEL, Johnston FE, Lohman TG, Pollock ML et al. Skinfold Thicknesses and Measurement Technique. In: Lohman TG, Roche AF, Martorell R (eds). Anthropometric Standardization Reference Manual. Champaing, Illinois: Human Kinectics; 1988. p.55.
13. Ellis K. Human body composition: In vivo methods (Dual - Energy X - Ray Absorptiometry). Physiol Rev. 2000;80,p.662.

14. American Geriatrics Society Panel on Exercise and Osteoarthritis. Exercise prescription for older adults with osteoarthritis pain - Consensus practice recommendations: a supplement to the AGS Clinical Practice Guidelines on the management of chronic pain in older adults. J Am Geriatr Soc. 2001;49:808-23.

15. Williams MA, Haskell WL, Ades PA, Amsterdam EA, Bittner V, Franklin BA et al. Resistance exercise in individuals with and without cardiovascular disease: 2007 update. Circulation. 2007;116:572-84.

16. Guralnik JM, Ferrucci L, Simonsick EM, Salive ME, Wallace RB. Lower-extremity function in persons over the age of 70 years as a predictor of subsequent disability. New Engl J Med. 1995;332:55661.

17. Center for Diseases Control. Revised classification system for HIV infection and expanded surveillance case definition for AIDS among adolescents and adults. MMWR. 1993;41(RR-17). www.cdc.gov/ MMWR/preview/MMWRhtml/00018871.htm (Apr 10, 2008)

18. Fiatarone MA, O’Neill EF, Ryan ND, Clements KN, Solares GR, Nelson $\mathrm{ME}$, et al. Exercise training and nutrition supplementation for physical frailty in very elderly people. N Engl J Méd. 1994;330:1769-75.

19. Malita FM, Karelis AD, Toma E, Rabasa-Lhoret R. Effects of different types of exercise on body composition and fat distribution in HIVinfected patients: A brief review. Can J Appl Physiol. 2005;30:23345 .

20. Sullo A, Brizzi G, Meninno V, Mercadante F, Cardinale P. Morphofunctional modification induced by a training protocol in the elderly. Medicina dello Sport. 2003;56:57-62.

21. Bruunsgaard H, Pedersen BK. Effects of exercise on the immune system in the elderly population. Immunology and Cell Biology.2000;78:523-31.

22. Paw MJMCA, De Jong N, Pallast EGM, Kloek GC, Schouten EG, Kok FJ Immunity in frail elderly: a randomized controlled trial of exercise and enriched foods. Med Sci Sports Exerc. 2000;32:2005-11. 